\title{
Thermal and irradiation resistance of folic acid encapsulated in zein ultrafine fibers or nanocapsules produced by electrospinning and electrospraying
}

\author{
Jarine Amaral do Evangelho ${ }^{\mathrm{a}}$, Rosane Lopes Crizel ${ }^{\mathrm{a}}$, Fabio Clasen Chaves ${ }^{\mathrm{a}}$, Luciana Prietto ${ }^{\mathrm{a}}$, \\ Vânia Zanella Pinto ${ }^{\mathrm{a}}$, Martha Zavariz de Miranda ${ }^{\mathrm{b}}$, Alvaro Renato Guerra Dias ${ }^{\mathrm{a}}$, \\ Elessandra da Rosa Zavareze $\mathrm{a}^{\mathrm{a}, *}$
}

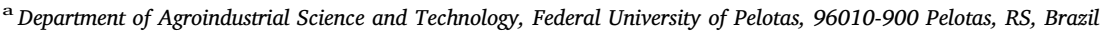

${ }^{\mathrm{b}}$ Brazilian Agricultural Research Corporation, Embrapa Wheat, P.O. Box 3081, 99050-970 Passo Fundo, RS, Brazil.

\section{A R T I C L E I N F O}

\section{Keywords:}

Temperature

UVA irradiation

Vitamin

Stability

\begin{abstract}
A B S T R A C T
The objectives of this study were to characterize zein fibers and capsules prepared by electrospinning and electrospraying techniques, respectively, and then use them to encapsulate folic acid. Folic acid containing fibers and capsules $(0.5,1.0$, and $1.5 \%, \mathrm{w} / \mathrm{v})$ were submitted to thermal treatment $\left(100,140\right.$, and $\left.180{ }^{\circ} \mathrm{C}\right)$ and $\mathrm{ul}-$ traviolet A light (UVA) irradiation to evaluate the resistance of folic acid. Zein fibers and capsules containing folic acid showed high encapsulation efficiency ( $>80 \%$ ). Unencapsulated folic acid showed a reduction in folic acid content from $17.17 \mu \mathrm{g} / \mathrm{mL}$ to $5.44 \mu \mathrm{g} / \mathrm{mL}$ (approximately $70 \%$ ) when exposed to $180{ }^{\circ} \mathrm{C}$. Photodegradation of unencapsulated folic acid lowered its concentration from $17.17 \mu \mathrm{g} / \mathrm{mL}$ to $12.58 \mu \mathrm{g} / \mathrm{mL}(\sim 26 \%$ of reduction), when exposed for $1 \mathrm{~h}$ to UVA irradiation. However, folic acid concentration when encapsulated in fibers (1.5\%) was maintained or only slightly reduced from $9.73 \mu \mathrm{g} / \mathrm{mg}$ to $8.88 \mu \mathrm{g} / \mathrm{mg}$ after thermal treatment at $180{ }^{\circ} \mathrm{C}$. The capsules containing $1.5 \%$ of folic acid also presented a slight reduction in folic acid concentration from $8.84 \mu \mathrm{g} /$ $\mathrm{mg}$ to $7.88 \mu \mathrm{g} / \mathrm{mg}$ when exposed to $24 \mathrm{~h}$ of UVA irradiation. Zein fibers and capsules containing folic acid present promising characteristics for application in foods that require thermal processing or exposure to irradiation.
\end{abstract}

\section{Introduction}

Folic acid, also known as vitamin B9, is an essential component of a healthy diet. This micronutrient is the precursor of several enzymatic cofactors required for the synthesis of nucleic acids, amino acid interconversion, and DNA and RNA methylation reactions (Scott, Rebeill, \& Fletcher, 2000). Folate deficit in the diet can lead to various disorders, such as congenital defects, cardiovascular disease, megaloblastic anemia, Alzheimer's disease, and cancers (Agrawal, Murphy, \& Agrawal, 2007; Gazzali et al., 2016; Nukolova, Oberoi, Cohen, Kabanov, \& Bronich, 2011).

Folic acid consists of an aromatic pteridine ring attached to $p$-aminobenzoic acid, which in turn is associated with one or more glutamic acids. When the chemical structure breaks down, the formed products are biologically inactive (Delchier, Herbig, Rychlik, \& Renard, 2016). The chemical reactivity of folic acid makes this vitamin one of the most susceptible to losses during food storage and processing. Factors such as temperature, light, $\mathrm{pH}$, and the presence of catalysts or oxidizing agents contribute to the degradation of folic acid (Nguyen, Oey, Verlinde, Van Loey, \& Hendrickx, 2003; Fukuwatari et al., 2009; Jastrebova et al., 2013).

Due to the low stability of folic acid, it is necessary to add high concentrations of this vitamin in the fortification of foods to ensure their health promotion effect (Acevedo-Fani, Soliva-Fortuny, \& MartínBelloso, 2018). Ingestion above recommended levels may lead to the appearance of unmetabolized folic acid in fetal and maternal circulation. It has been suggested that unmetabolized folic acid in maternal and fetal blood may act as a methyl donor for the regulation of gene expression, with consequences to fetal formation (Silva, Keating, \& Pinto, 2017). Considering the importance of folic acid to human health, its vulnerability to external agents, and the potential risks associated with overeating, folic acid encapsulation may provide an alternative to its degradation in food products and an increase in its bioaccessibility. The encapsulation process may increase the bioaccessibility of folic

\footnotetext{
* Corresponding author.

E-mail addresses: martha.miranda@embrapa.br (M.Z.d. Miranda), zavareze@pq.cnpq.br (E.d.R. Zavareze).
} 
acid, making it available for absorption in the small intestine. Thus, it is suggested that encapsulation also promotes increased bioavailability, as it is one of the most available forms for metabolization and distribution of physical activity.

Electrospinning and electrospraying techniques are versatile methods to encapsulate compounds, with a number of advantages when compared to traditional encapsulation techniques such as spray drying, coacervation, or ionic gelation. Among their advantages are the non-use of high temperatures, the high surface area and small diameter of the resultant fibers and capsules, and the high encapsulation efficiency (Aceituno-Medina, Mendoza, Lagaron, \& Lopez-Rubio, 2015; Bhushani \& Anandharamakrishnan, 2014; Zussman, 2011). The difference between electrospinning and electrospraying techniques is based on the concentration of the polymer solution. When the concentration of the solution is high (electrospinning), the jet exiting the capillary is in the form of a fiber and performs a whip-like motion until it reaches the collector plate. The solvent is evaporated during the process, resulting in the deposition of a solid nanofiber under the grounded bulkhead (Jaworek \& Sobczyk, 2008). When the concentration of the polymer solution is low (electrospraying), droplets are formed. These highly charged droplets are self-dispersing and evaporation of the solvent leads to solidification, resulting in nanoparticles and nano-clusters on the collector.

The use of proteins for the micro- and nano-encapsulation of bioactive compounds has the advantage of non-toxicity for application in food and drugs (Ariyarathna \& Karunaratne, 2015). Zein, the main storage protein of maize, is considered a safe food ingredient by the Food and Drug Administration (FDA); however, due to its hydrophobic character and its deficiency in amino acids (such as lysine and tryptophan), the use of corn protein in food products is limited. Zein is used in the manufacture of a wide variety of products, including textile fibers (Selling et al., 2007), biodegradable films, and packaging (Padgett, Han, \& Dawson, 1998), and for the encapsulation of food and pharmaceutical products (Guo, Heinamaki, \& Yliruusi, 2008).

Zein nanofibers produced by electrospinning showed an increased stability and bioavailability of gallic acid (Neo et al., 2013), $\beta$-carotene (Fernandez, Torres-Giner, \& Lagaron, 2009), curcumin (Brahatheeswaran et al., 2012), $\alpha$-tocopherol (Saowakon \& Suanantha, 2014), ferulic acid (Yang, Zha, Yu, \& Liu, 2013), and tannins (Mori et al., 2014). Torres-Giner, Martinez-Abad, Ocio, and Lagaron (2010) produced zein capsules by an electrospraying process with docosahexaenoic acid (DHA, Omega-3) and reported the delay of oxidation reactions and an increase in chemical stability of the DHA. Peñalva et al. (2015), in a study using zein to encapsulate folic acid by spray-drying for pharmaceutical applications, evaluated the ability of zein nanoparticles to improve the bioavailability of folic acid. However, there are no studies on the evaluation of the thermal resistance of folic acid encapsulated with zein by electrospraying or electrospinning at temperatures simulating the processing of food for application in the food industry. In addition, research is needed to evaluate the exposure of encapsulated folic acid to different levels of ultraviolet irradiation.

Since encapsulation could improve the resistance of folic acid, the objective of this work was to evaluate the resistance of encapsulated folic acid in zein ultrafine fibers or capsules produced by the technique of electrospinning/electrospraying to thermal and UVA irradiation treatments.

\section{Materials and methods}

\subsection{Materials}

Folic acid and zein were purchased from Sigma-Aldrich. The other reagents were of analytical grade.

\subsection{Preparation of the polymer solution}

Polymer solutions of pure zein and zein with folic acid were used to prepare ultrafine fibers by electrospinning and capsules by electrospraying. Polymer solutions were prepared using 30\% (w/v) zein for fiber formation and $9 \%(\mathrm{w} / \mathrm{v})$ zein for capsule formation in $70 \%(\mathrm{v} / \mathrm{v})$ ethanol solution containing sodium carbonate $\left(0.01 \mathrm{~mol} \mathrm{~L}^{-1}\right)$. The polymer solutions were stirred using a magnetic stirrer for $2 \mathrm{~h}$. Polymeric solutions of zein and folic acid were prepared under the same conditions, but with the addition of folic acid at concentrations of 0.5 , 1.0 , and $1.5 \%(\mathrm{w} / \mathrm{w})$. The concentrations of zein and folic acid were determined based on preliminary tests to obtain fibers or capsules with uniform morphology.

\subsection{Characterization of polymer solutions}

The polymer solutions were characterized by apparent viscosity and electrical conductivity. The apparent viscosity was determined in a Brookfield digital viscometer with a spindle (No. 18, model DV-II, USA). The electrical conductivity was evaluated with a conductivity meter (Tecnopom model - mCA-150P), and expressed in $\mu \mathrm{S} / \mathrm{cm}$. The evaluations were performed at room temperature $\left(\sim 23^{\circ} \mathrm{C}\right)$ using a $20 \mathrm{~mL}$ sample for each analysis.

\subsection{Production of fibers/capsules by electrospinning/electrospraying}

The equipment used to make the fibers and capsules, located inside a closed chamber, consisted of a high voltage source $(-30 /+30 \mathrm{kV}$, Instor, England), an infusion pump (kdScientific, Model 200, England), and a fixed collector, mounted horizontally. Each polymer solution was individually placed in a $1 \mathrm{~mL}$ syringe with a $0.7 \mathrm{~mm}$ diameter stainless steel outlet port. For fiber and capsule production, the feed rates used were $1.0 \mathrm{~mL} / \mathrm{h}$ and $0.6 \mathrm{~mL} / \mathrm{h}$, respectively. The electrospinning/electrospraying process was conducted by connecting the positive electrode $(+16 \mathrm{kV})$ from the DC power source (INSTOR, INSES-HV30, Brazil) to the needle. A negative electrode was connected to a stainless steel collector that was covered with aluminum foil and positioned horizontally to the infusion pump for deposition of the material. The distance from the tip of the needle to the collecting target was $16 \mathrm{~cm}$ for fiber formation and $10 \mathrm{~cm}$ for capsule formation. The process was controlled at $23 \pm 2{ }^{\circ} \mathrm{C}$ by an air conditioner and the relative humidity was set at $45 \pm 2 \%$ using a dehumidifier.

\subsection{Fiber and capsule morphology and diameters}

Fibers and capsule morphology was evaluated by scanning electron microscopy (SEM) (Jeol, JSM-6610LV, USA). A small portion of the material was fixed in stubs using a double-sided tape and covered with gold using a metallizer (Sputtering, Deston Vacuum Deskv, USA). Images were captured under an acceleration voltage of $10 \mathrm{kV}$ with a magnification of 1000 and $10,000 \times$ for the fibers and 5000 and $30,000 \times$ for the capsules. Mean diameter was determined from the calculated average of 50 fibers/capsules obtained from the SEM images, using the ImageJ computer program.

\subsection{Functional groups}

Functional groups and interactions of unencapsulated and encapsulated folic acid in the form of zein fibers and capsules were evaluated on a Fourier Transform Infrared (FTIR) spectrometer (Shimadzu, IRAffinity, Japan) with an ATR (Attenuated Total Reflectance) accessory. Scans were performed in the spectral range of 800 to $4000 \mathrm{~cm}^{-1}$, and 32 readings were collected at a resolution of $2 \mathrm{~cm}^{-1}$. The signals were processed using IRsolution software. 


\subsection{Thermogravimetric analysis (TGA)}

Thermogravimetric analysis of unencapsulated and encapsulated folic acid in the form of fibers and capsules was carried out according to the method of Ariyarathna and Karunaratne (2015) by a thermogravimetric analyzer (TGA, TA-60WS, Shimadzu, Kyoto, Japan). Samples (approximately $5 \mathrm{mg}$ ) were heated in platinum capsules in the range of 30 to $600{ }^{\circ} \mathrm{C}$, with a heating rate of $10^{\circ} \mathrm{C} \mathrm{min}^{-1}$ and a nitrogen flow of $50 \mathrm{~mL} \min ^{-1}$. An empty platinum capsule was used as a reference.

\subsection{Encapsulation efficiency}

The encapsulation efficiency of folic acid in the zein fibers or capsules was assessed by determining the total folic acid present in the material and the content of encapsulated folic acid. The sample $(10 \mathrm{mg})$ was dissolved in 5 to $15 \mathrm{~mL}$ of $70 \%$ ethanol and $20 \mu \mathrm{L}$ sodium hydroxide $\left(1 \mathrm{~mol} \mathrm{~L}^{-1}\right)$, then vortexed for $2 \mathrm{~min}$; and for complete solubilization, the samples were sonicated for $5 \mathrm{~min}$. The material was centrifuged for $5 \mathrm{~min}$ at $2935 \times g$ and filtered using a nylon membrane $(0.22 \mu \mathrm{m})$. To determine the content of encapsulated folic acid, a rinse with ultrapure water was first performed to remove folic acid that had not been encapsulated, and then the material was vortexed and sonicated as described above. These materials were analyzed by high performance liquid chromatography (HPLC; Shimadzu, Japan) coupled to a high-resolution quadrupole-time-of-flight mass spectrometer (MSQTof, Bruker Daltonics, Bremen, Germany). For chromatographic separation a Diol-75 $(100 \mathrm{~mm} \times 2.1 \mathrm{~mm})$ column (MicroSolv Technology Corporation, Leland, NC, USA) was used. The mobile phases were water acidified with $0.1 \%$ formic acid (eluent $\mathrm{A}$ ) and acetonitrile acidified with $0.1 \%$ formic acid (eluent B). The flow rate was $0.2 \mathrm{~mL} \cdot \mathrm{min}^{-1}$ and the column temperature was maintained at $40^{\circ} \mathrm{C}$. The mass spectrometer was operated in the ESI positive mode, with spectra acquired over a mass range of $m / z 50$ to 1200 . MS parameters were: $4 \mathrm{kV}$ capillary voltage, nebulizing gas pressure $\left(\mathrm{N}_{2}\right)$ of 2 bars, drying gas at $8 \mathrm{~L} \mathrm{~min}^{-1}$, source temperature of $180^{\circ} \mathrm{C}$, and a RF collision of $150 \mathrm{Vpp}$; then $70 \mathrm{mS}$ was transferred, with a pre-pulse storage of $5 \mathrm{mS}$. The equipment was calibrated with $10 \mathrm{mM}$ sodium formate, covering the entire acquisition range ( $\mathrm{m} / \mathrm{z} 50$ to 1200$)$. In addition, automatic MS/ MS experiments were performed by adjusting the collision energy values as follows: $m / z 100,15 \mathrm{eV} ; \mathrm{m} / z 500,35 \mathrm{eV} ; \mathrm{m} / z 1000,50 \mathrm{eV}$, using nitrogen as the collision gas. The encapsulation efficiency (E) was calculated according to Eq. 1.

$E(\%)=\frac{\text { Encapsulated Folic Acid Content }}{\text { Total Folic Acid Content }} \times 100$

\subsection{Thermal and UVA irradiation resistance}

The resistance of unencapsulated and encapsulated folic acid in the fiber or capsule form was evaluated at temperatures of 100,140, and $180^{\circ} \mathrm{C}$ for $45 \mathrm{~min}$; and under exposure to UVA irradiation $(\lambda 365 \mathrm{~nm})$ for 1,12 , and $24 \mathrm{~h}$. After the heating or irradiation exposure, $10 \mathrm{mg}$ samples containing $0.5,1.0$, or $1.5 \%(\mathrm{w} / \mathrm{w})$ of fibers or capsules, were diluted in 5,10 or $15 \mathrm{~mL}$ of ethanol $(70 \%$; v/v), respectively, and homogenized in a vortex for $2 \mathrm{~min}$. For complete solubilization, the samples were sonicated for $5 \mathrm{~min}$. The material was centrifuged for $5 \mathrm{~min}$ at $2395 \times g$ and filtered using a nylon membrane $(0.22 \mu \mathrm{m})$. The sample of $10 \mathrm{mg}$ of unencapsulated folic acid was first diluted in $10 \mathrm{~mL}$ of ethanol (70\%; v/v) and an aliquot of this solution was diluted $125 \times$ for calibration. Folic acid was analyzed by liquid chromatography mass spectrometry (LC-MS), as described in item 2.8. The amounts of folic acid encapsulated were expressed in $\mu \mathrm{g} / \mathrm{mg}$ of fibers or capsules and the unencapsulated folic acid in $\mu \mathrm{g} / \mathrm{mL}$ of ethanol.

The products of degradation of unencapsulated folic acid, exposed at $180^{\circ} \mathrm{C}$ or $24 \mathrm{~h}$ of UVA irradiation, were also evaluated by LC-MS. MS data were analyzed using Data Analysis 4.0 software (Bruker Daltonics,
Bremen, Germany). The identification was performed by comparing the high-resolution $m / z$ and $\mathrm{MS}^{\mathrm{n}}$ fragmentation patterns with data from databases (METLIN, KEGG compounds, PubChem, Mass Bank, Maven, FooDB, and ReSpect) and reference literature with a mass accuracy window of $5 \mathrm{ppm}$.

\subsection{Statistical analysis}

Analytical determinations for the samples were performed in triplicate and standard deviations were reported. All data was subjected to an analysis of variance (ANOVA) and means of electrical conductivity and viscosity for different zein solutions with varying folic acid concentrations $(0,0.5,1.0$, and $1.5 \% ; \mathrm{w} / \mathrm{w})$ and means for encapsulation efficiency, thermal resistance, irradiation resistance of encapsulation, and percentage of folic acid were compared by Tukey's test $(p<.05)$.

\section{Results and discussion}

\subsection{Characterization of polymer solutions}

The electrical conductivity and apparent viscosity of zein solutions with different concentrations of folic acid are shown in Table 1 . The electrical conductivity of the solution is influenced by the type and concentration of the polymer, the solvent, and the availability of ionizable compounds (Bhardwaj \& Kundu, 2010). The electrical conductivity values of the solutions with $30 \%(\mathrm{w} / \mathrm{v})$ zein were higher than those of the $9 \%(\mathrm{w} / \mathrm{v})$ solutions of the polymer (Table 1$)$. The higher electrical conductivity in the solutions with a higher concentration of zein is associated with an increase of ionizable groups in solution. There are also electrostatic hydrogen bond interactions between the $\mathrm{NH}$ of the zein and the CO of folic acid. In both, $30 \%$ and $9 \%$ zein solutions, the addition of folic acid reduced the electrical conductivity. However, this reduction did not affect the formation of fibers and capsules, since there was a continuous and stable jet formation allowing the production of continuous fibers and capsules, indicating that the incorporation of the vitamin did not negatively affect the electrospinning/electrospraying process.

The polymer solution with $9 \%(\mathrm{w} / \mathrm{v})$ zein had a very low viscosity and it was not possible to determine the apparent viscosity with the equipment available. The addition of folic acid in the $30 \%$ zein polymer solution increased its apparent viscosity, suggesting an interaction between folic acid and the protein. According to Aytac, Kusku, Durgun, and Uya (2016), this increase in the viscosity is due to a greater entanglement of polymer chains in solution. The increase in viscosity and the reduction in electrical conductivity of the polymer solutions containing folic acid did not influence the process of fiber and capsule

Table 1

Apparent viscosity and electrical conductivity of $30 \%$ and $9 \%$ zein solutions with different concentrations of folic acid.

\begin{tabular}{|c|c|c|c|}
\hline \multicolumn{2}{|c|}{ Polymer solution* } & \multirow{2}{*}{$\begin{array}{l}\text { Electric conductivity ( } \mu \mathrm{S} / \\
\mathrm{cm})\end{array}$} & \multirow{2}{*}{$\begin{array}{l}\text { Viscosity apparent } \\
(\mathrm{cP})\end{array}$} \\
\hline $\begin{array}{l}\text { Zein }(\% ; \mathrm{m} / \\
\text { v) }\end{array}$ & $\begin{array}{l}\text { Folic acid (\%; } \\
\mathrm{m} / \mathrm{v})\end{array}$ & & \\
\hline 30 & 0.0 & $1330.0 \pm 4.3^{\mathrm{a}}$ & $104.9 \pm 6.3^{\mathrm{d}}$ \\
\hline 30 & 0.5 & $1255.7 \pm 4.5^{\mathrm{b}}$ & $121.3 \pm 3.4^{\mathrm{c}}$ \\
\hline 30 & 1.0 & $1201.7 \pm 5.9^{c}$ & $133.3 \pm 3.2^{\mathrm{b}}$ \\
\hline 30 & 1.5 & $1158.0 \pm 4.3^{\mathrm{d}}$ & $143.3 \pm 2.0^{\mathrm{a}}$ \\
\hline 9 & 0.0 & $1046.7 \pm 2.1^{\mathrm{a}}$ & n.d \\
\hline 9 & 0.5 & $1041.3 \pm 1.2^{\mathrm{b}}$ & n.d \\
\hline 9 & 1.0 & $995.3 \pm 1.6^{\mathrm{c}}$ & n.d \\
\hline 9 & 1.5 & $988.0 \pm 0.5^{\mathrm{d}}$ & n.d \\
\hline
\end{tabular}

* Different letters among the same concentration of zein solutions in the same column represent a significant difference among the averages submitted to the Tukey test at 5\% of significance. n.d: not detected. 

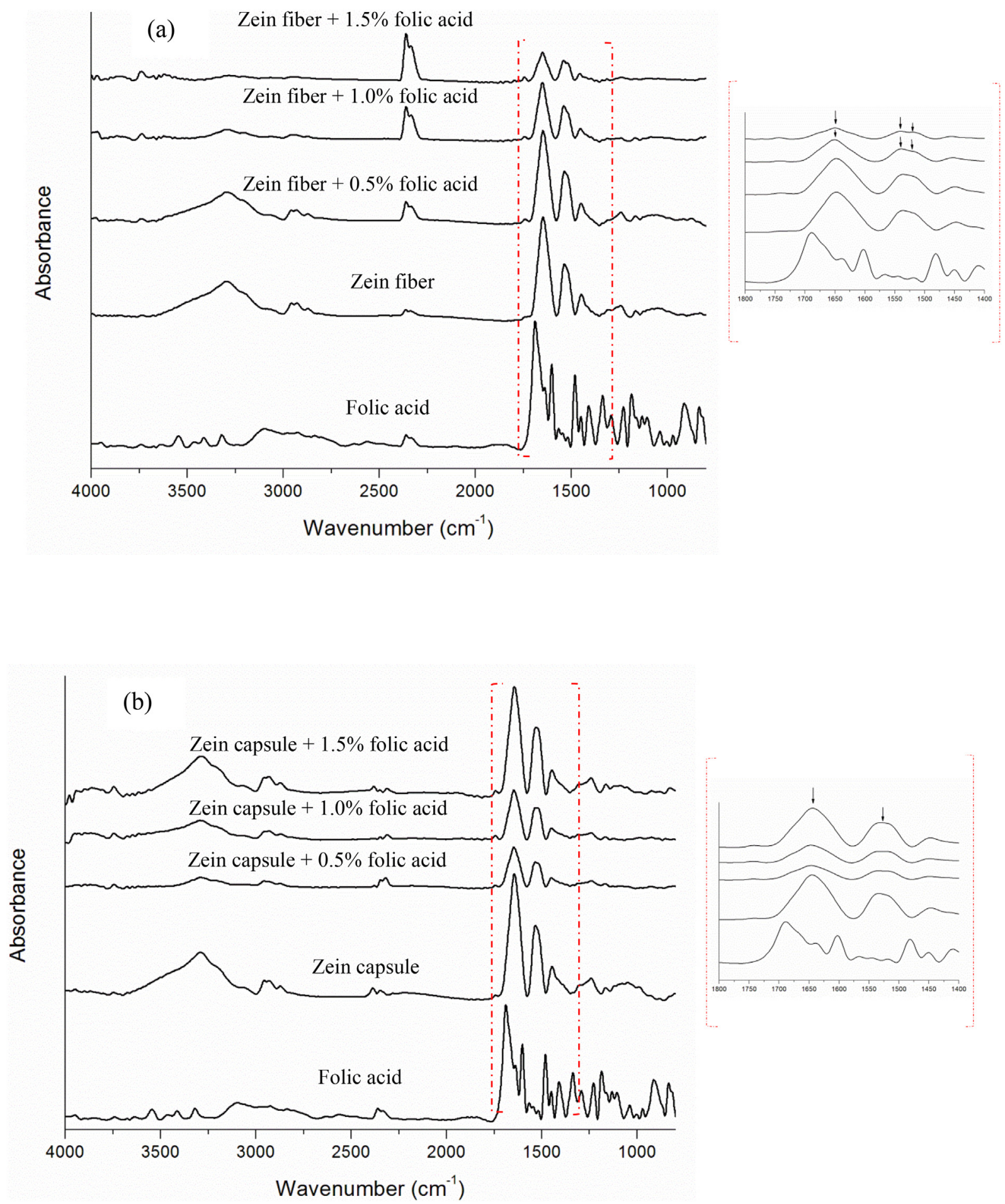

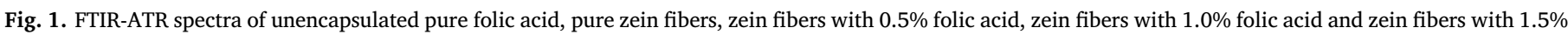
of folic (a); and zein capsules with $0.5 \%$ folic acid, zein capsules with $1.0 \%$ folic acid and zein capsules with $1.5 \%$ folic acid (b).

formation; however, it caused an increase in their average diameter. In general, a higher viscosity and lower electrical conductivity result in a smaller jet stretch of the solution, thus producing thicker fibers (Wen et al., 2016). Pérez-Masiá et al. (2015) observed similar results, including increased viscosity and reduced electrical conductivity, by adding folic acid to milk protein solution.

\subsection{Functional groups}

FTIR analysis was performed to evaluate the interactions between zein and folic acid (Fig. 1). The spectrum of unencapsulated pure folic acid is characterized by absorption bands in the regions of $4000 \mathrm{~cm}^{-1}$ and $\sim 900 \mathrm{~cm}^{-1}$ (Fig. 1a and b). Bands characteristic of $\mathrm{C}=\mathrm{O}$ deformation are observed at $\sim 1695 \mathrm{~cm}^{-1}$, while the overlapped band $\left(\sim 1607 \mathrm{~cm}^{-1}\right)$ refers to $\mathrm{N}-\mathrm{H}$ vibration. The band $1481 \mathrm{~cm}^{-1}$ is attributed to the vibration of phenyl ring and of pteridine. The folic acid bands observed in this study are in agreement with the work of Aceituno-Medina et al. (2015) and Assadpour, Jafari, and Maghsoudlou.Y. (2017).

Pure zein fibers and capsules show amide I and II bands identified at 
$\sim 1643 \mathrm{~cm}^{-1}$ and $\sim 1530 \mathrm{~cm}^{-1}$, respectively (Fig. $1 \mathrm{a}$ and b). The amide I band is related to $\mathrm{C}=\mathrm{O}$ bond stretching and the amide II band is associated with the symmetrical deformation of the $\mathrm{N}-\mathrm{H}$ bond. However, the bands in the 3995 to $2872 \mathrm{~cm}^{-1}$ region refer to an $\mathrm{O}-\mathrm{H}$ stretch superimposed on the $\mathrm{N}-\mathrm{H}$ stretch and asymmetric and symmetric $\mathrm{C}-\mathrm{H}$ stretches relative to the free fatty acid derivatives present in zein (Dashdorj et al., 2015).

The encapsulation of 1.0 and $1.5 \%$ folic acid by zein fibers promoted a displacement of the amide I band, since the $1643 \mathrm{~cm}^{-1}$ band in the pure zein fibers shifted to $1651 \mathrm{~cm}^{-1}$ in the fibers containing folic acid, for both concentrations. There is an overlap of the characteristic band of amide II folic acid observed as a small shoulder at $1515 \mathrm{~cm}^{-1}$, and the band for zein fibers at $1539 \mathrm{~cm}^{-1}$ (Fig. 1a). In these spectra, the disappearance of the characteristic $\mathrm{O}-\mathrm{H}$ stretch band $\left(\sim 3000-3600 \mathrm{~cm}^{-1}\right)$ is observed, which suggests the formation of hydrogen interactions between components of the fiber (Chen, Xiumei, \& Fengling, 2007). Aceituno-Medina et al. (2015) reported similar spectra for fibers developed with folic acid, amaranth protein, and pullulan.

FTIR-ATR spectra for the pure zein and folic acid-containing zein capsules are shown in Fig. 1b. In general, there was no modification of the protein secondary structure, since no spectral band shifts are observed for 0.5 and $1.0 \%$ folic acid capsules. However, for capsules with $1.5 \%$ folic acid, there was a displacement in the amide I and II bands, since they are observed in the pure zein capsules at $1643 \mathrm{~cm}^{-1}$ and $1530 \mathrm{~cm}^{-1}$, and in the capsules containing folic acid these are shifted to $1642 \mathrm{~cm}^{-1}$ and $1523 \mathrm{~cm}^{-1}$, respectively. Some studies have reported that folic acid is able to conjugate with different polymers through an interaction of the amide II $(\mathrm{NH})$ with the carboxylic group of the bioactive $(C=O)$, which can be evidenced by the displacement observed for the capsules containing $1.5 \%$ folic acid (Sudimack \& Lee, 2000; Teng et al., 2013).

Interaction of the polymer with the vitamin is important for improving its resistance to different conditions of exposure with variations in processing, as well as after its consumption. Zein nanoparticles help protect the folic acid from the gastric environment, where free folic acid can precipitate, and act as folic acid carriers for the absorptive membrane of the intestine. The properties of zein would be responsible for an increase in the lifetime of folic acid in the upper gastrointestinal tract, where its absorption is favored (Peñalva et al., 2015).

\subsection{Morphology and size distribution of fiber/capsule diameter}

Zein fibers and capsules containing $0.0 \%, 0.5 \%, 1.0 \%$, and $1.5 \%$ of folic acid were observed by SEM to characterize their morphology and average diameters (Figs. 2 and 3). The conditions used in processing allowed the formation of fibers and smooth particles with homogeneous and continuous formats. The addition of folic acid did not affect the morphology of the fibers and capsules; however, the mean diameter in both treatments was altered. This can be attributed to the increased viscosity of the solutions when incorporating folic acid (Table 1). The mean diameter of fibers ranged from $369 \mathrm{~nm}$ for zein-only fibers (Figs. 2a-b) to $702 \mathrm{~nm}$ for fibers with zein and $1.5 \%$ folic acid (Figs. $2 \mathrm{~g}$ h). For capsules, those containing $0.5 \%$ of folic acid had the lowest mean diameter of $268 \mathrm{~nm}$ (Figs. 3c-d), while those containing $1.0 \%$ of folic acid had the largest mean diameter of $407 \mathrm{~nm}$ (Figs. 3e-f). Altan, Aytac, and Uyar (2018) also used 30\% zein solutions and reported a mean diameter of pure zein fibers at $604 \mathrm{~nm}$, whereas zein fibers containing 5,10 , and $20 \%$ carvacrol, presented diameters of 647,539 , and $553 \mathrm{~nm}$, respectively. Baspinar, Ustundas, Bayraktar, and Sezgin (2018) used $5 \%$ zein solution for the encapsulation of curcumin by electrospraying and observed a range of capsule diameters between 300 and $600 \mathrm{~nm}$.

\subsection{Thermogravimetric analysis (TGA)}

TGA curves are shown in Fig. 4 of unencapsulated and encapsulated folic acid in the form of zein fibers and capsules containing $0.5,1.0$, and $1.5 \%(\mathrm{w} / \mathrm{v})$ folic acid. The thermogravimetric analysis was performed to observe if there was thermal protection of folic acid in zein fibers and capsules. Pure folic acid showed a water loss at about $125^{\circ} \mathrm{C}$ and its decomposition temperature was $257.73^{\circ} \mathrm{C}$. The decomposition temperature of folic acid in the fibers varied from 305 to $313^{\circ} \mathrm{C}$, whereas for the capsules this ranged from 298 to $303^{\circ} \mathrm{C}$ (Fig. 4a). Therefore, the incorporation of folic acid in the form of zein fibers and capsules, produced by electrospinning/electrospraying, contributes to an increase of the thermal resistance of the vitamin. These results suggest that the encapsulated form can be used in thermal processing, such as bakery products, which use high temperatures. Aceituno-Medina et al. (2015) also reported an increase in the thermal resistance of folic acid in fibers from amaranth protein isolate and pullulan. Ariyarathna and Karunaratne (2015) reported a decomposition temperature of $293^{\circ} \mathrm{C}$ for folic acid encapsulated in chickpea protein using the freeze-drying process.

\subsection{Encapsulation efficiency and thermal and UVA irradiation resistance of folic acid}

Since folic acid powder is commonly added in wheat and corn flours for fortification purposes, the resistance of encapsulated folic acid was evaluated while heating in an oven for $45 \mathrm{~min}$ at temperatures of 100 , 140 , and $180^{\circ} \mathrm{C}$. Folic acid-fortified flours are consumed after thermal processing, so the thermal resistance evaluation conditions were chosen to simulate the baking processes of breads and cakes.

The unencapsulated folic acid exposed at $140^{\circ} \mathrm{C}$ and $180^{\circ} \mathrm{C}$ showed reductions of approximately $11 \%$ and $70 \%$, respectively, after thermal treatment (Table 2). Based on thermogravimetric analysis (Fig. 4), the decomposition temperature of folic acid is $257.73^{\circ} \mathrm{C}$; however, Vora et al. (2002) reported that at $180^{\circ} \mathrm{C}$, the breakdown of glutamic acid bonds occurs, and therefore the active function of the vitamin is lost.

Table 2 shows that thermal treatments at 100,140 , and $180^{\circ} \mathrm{C}$ did not influence the content of folic acid encapsulated in zein fibers at the $0.5 \%$ and $1.0 \%$ levels when compared to fibers without exposure to the heat treatment, indicating that there was thermal protection of the vitamin. A slight reduction in thermal resistance was seen in fibers containing $1.5 \%$ folic acid. The capsules with $0.5 \%$ of folic acid exposed to all the thermal treatments presented similar behavior to the capsules without exposure to high temperature, while the capsules with $1.0 \%$ and $1.5 \%$ of folic acid showed a slight decrease in folic acid content (Table 2). Ariyarathna and Karunaratne (2015) encapsulated folic acid in chickpea protein by freeze-drying, and evaluated the thermal degradation at 80,120 , and $160{ }^{\circ} \mathrm{C}$ for $30 \mathrm{~min}$. They reported thermal degradations of $18.3 \%, 29.0 \%$, and $33.8 \%$, respectively, for encapsulated folic acid; whereas for unencapsulated folic acid, there was thermal degradation of $25.9 \%, 42.7 \%$, and $52.9 \%$, respectively.

The resistance of the unencapsulated and encapsulated folic acid in the form of zein fibers and capsules was also evaluated by exposure to UVA irradiation for 1,12 , or $24 \mathrm{~h}$ (Table 3). Unencapsulated folic acid exposed to UVA irradiation for $1 \mathrm{~h}$ showed a reduction of approximately $26 \%$ compared to folic acid without exposure to UVA irradiation.

Zein fibers containing $0.5,1.0$, and $1.5 \%$ of folic acid, when exposed for 1 or $24 \mathrm{~h}$ of UVA irradiation, showed resistance comparable to fibers not exposed to irradiation (Table 3). The fibers exposed for 12 and $24 \mathrm{~h}$ of irradiation had a small reduction in vitamin resistance. The zein capsules, in general, showed resistance to UVA irradiation, with the exception of the capsule containing $1.0 \%$ of folic acid, exposed to irradiation for $12 \mathrm{~h}$, where a reduction in resistance of the compound was observed. The loss of vitamins, even when protected in the zein matrix, is very small however, when compared to that of the unencapsulated folic acid. Thus, protection of the compound by encapsulation using electrospinning and electrospraying was satisfactory.

According to Juzeniene, Tam, Iani, and Moa (2013), folic acid is 

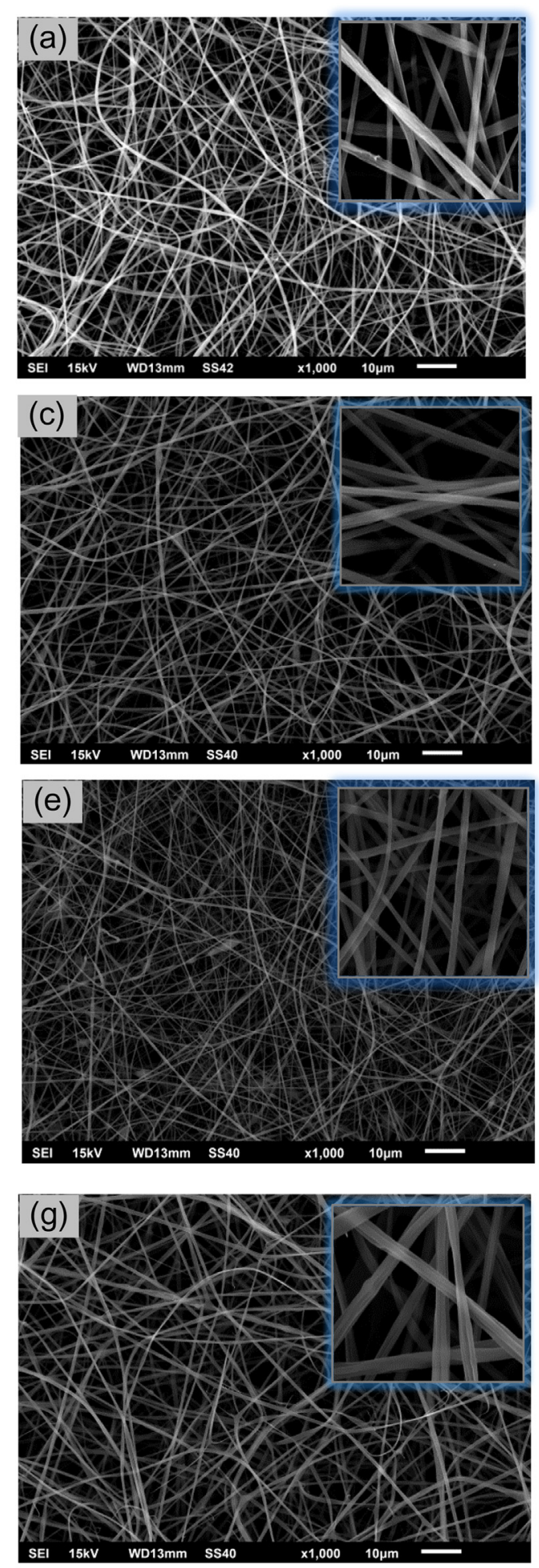

(b)

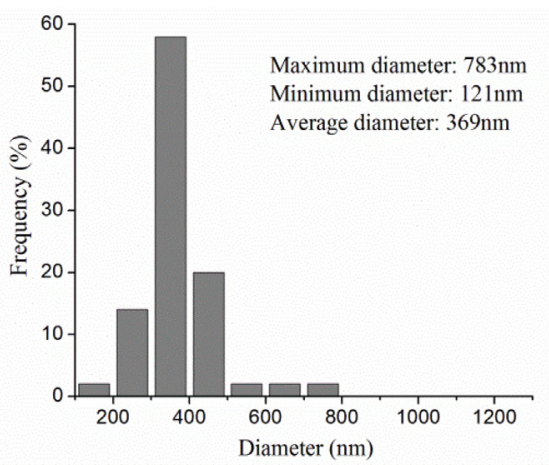

(d)

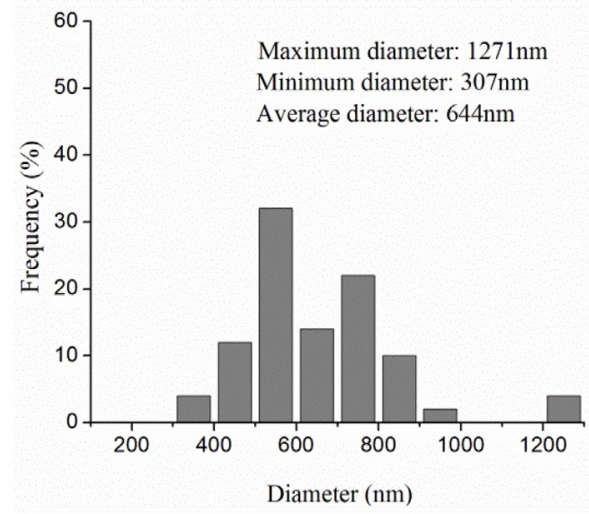

(f)

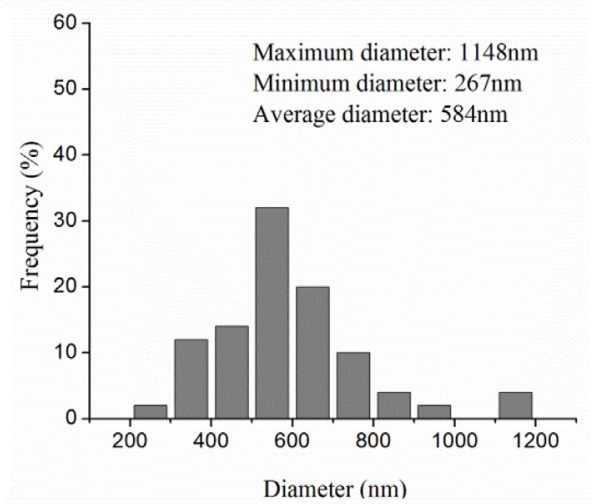

(h)

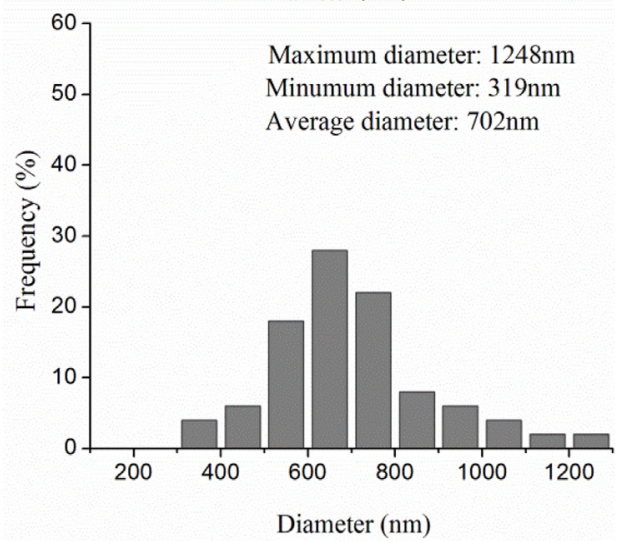

Fig. 2. Morphology of ultrafine fibers and respective size distribution: pure zein (a, b), zein with $0.5 \%$ folic acid (c, d), zein with $1.0 \%$ folic acid (e, f) and zein with $1.5 \%$ folic acid $(\mathrm{g}, \mathrm{h})$. Image with amplitude of $10,000 \times$ in the upper right corner of the SEM.

sensitive to UV irradiation due to excitation of the bonding between C9 and N10, leading to its cleavage and the formation of $p$-aminobenzoylL-glutamic acid, 6-formylpterin or 6-carboxypterin as photodegradation products. Zein is characterized by the predominance of hydrophobic amino acids such as proline, isoleucine, alanine, phenylalanine, methionine, valine, and leucine; while folic acid is a hydrophilic compound (Prasanna, Vasal, Kassahun, \& Singh, 2001). The resistance of folic acid in both fibers and capsules may be related to the interaction of the vitamin with these amino acids, which makes it difficult to cleave the C9-N10 bonding of folic acid. Perez-Maziá et al. (2015) encapsulated folic acid $(1.5 \% \mathrm{w} / \mathrm{v})$ in whey protein and resistant starch by electrospraying, and evaluated its photodegradation using natural 


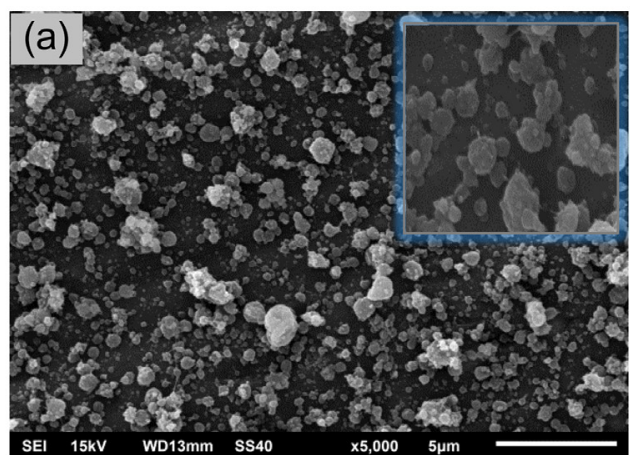

(b)
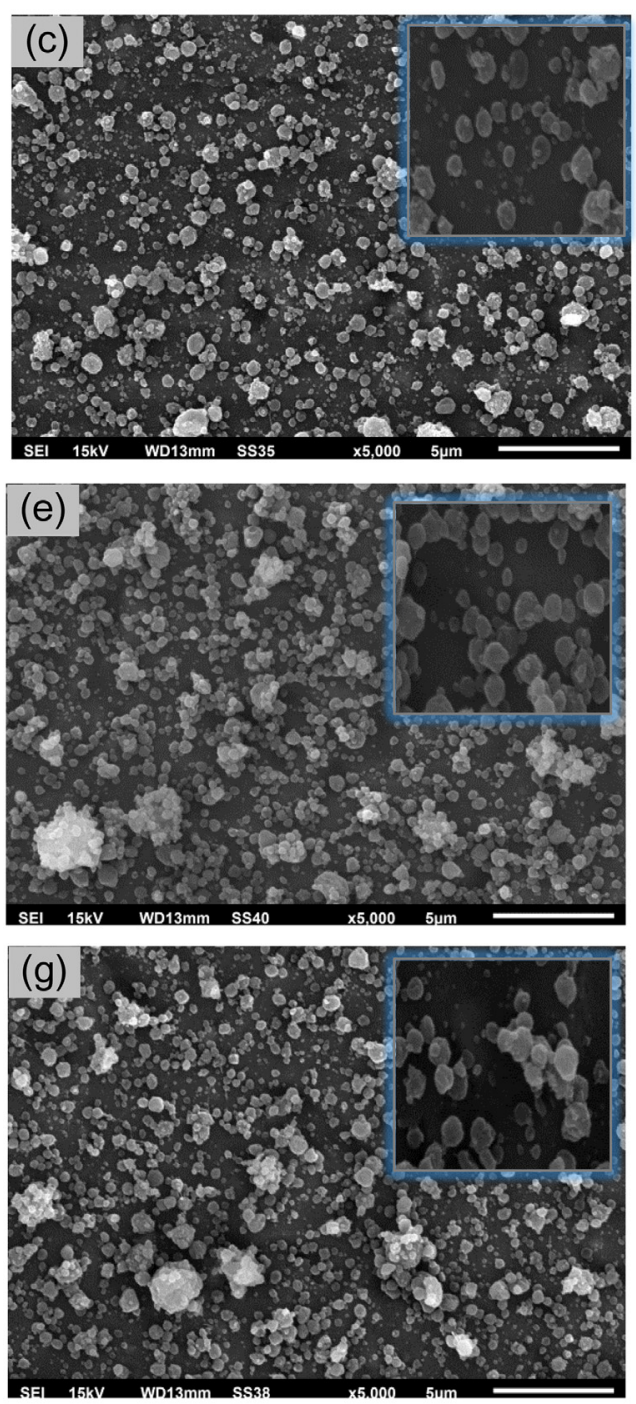

(d)

(f)

(h)
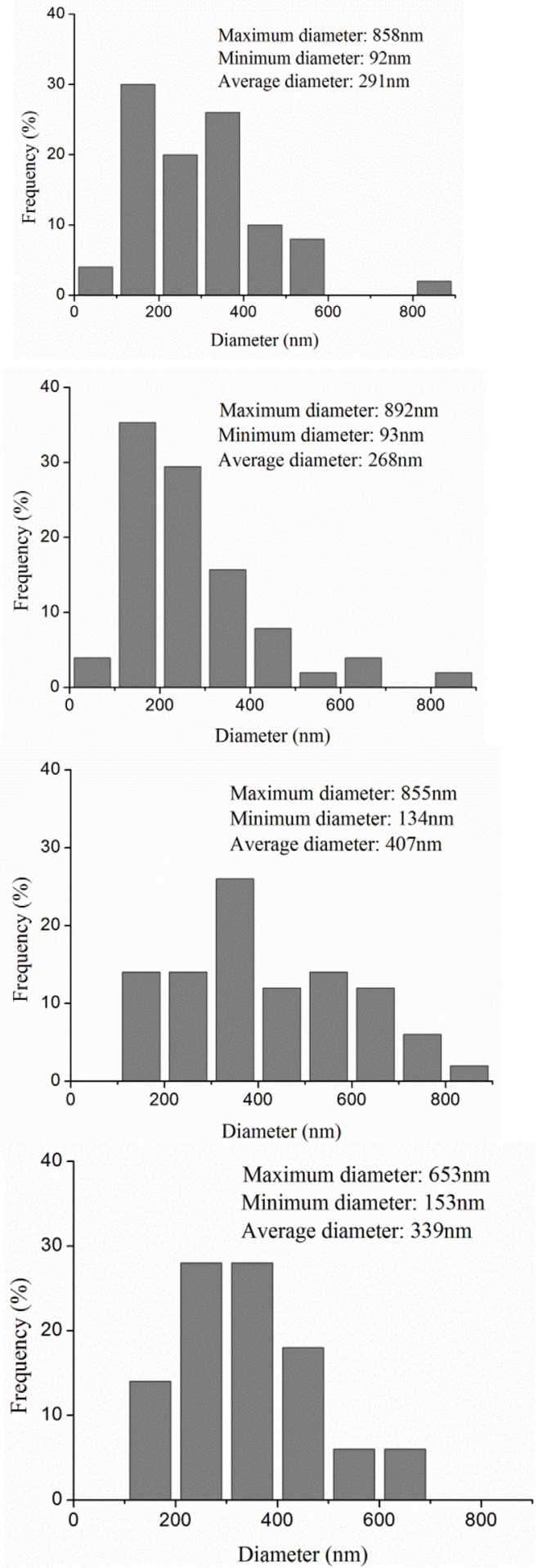

Fig. 3. Morphology of the capsules and their size distribution: pure zein (a, b), zein with $0.5 \%$ folic acid (c, d), zein with $1.0 \%$ folic acid (e, f) and zein with $1.5 \%$ folic acid $(\mathrm{g}, \mathrm{h})$. Image with amplitude of $30,000 \times$ in the upper right corner of the SEM.

irradiation and in the absence of irradiation over a period of 60 days. They observed that when folic acid was encapsulated with the protein, folic acid concentration was reduced by $41 \%$ when exposed to irradiation; whereas in the absence of irradiation, the degradation was only 9\%. In addition, folic acid encapsulated with resistant starch showed $88 \%$ degradation in the presence of irradiation, and in the dark this degradation was reduced to $37 \%$.

\subsection{Folic acid degradation products}

Based on the results of folic acid resistance, it was observed that exposure of unencapsulated folic acid to either temperature or irradiation promotes vitamin degradation. Therefore, the degradation compounds formed in these processes were investigated. A temperature of $180^{\circ} \mathrm{C}$ and exposure time to irradiation of $24 \mathrm{~h}$ were the parameters chosen for product identification, since these treatments are the most drastic and show the greatest degradation of folic acid. 

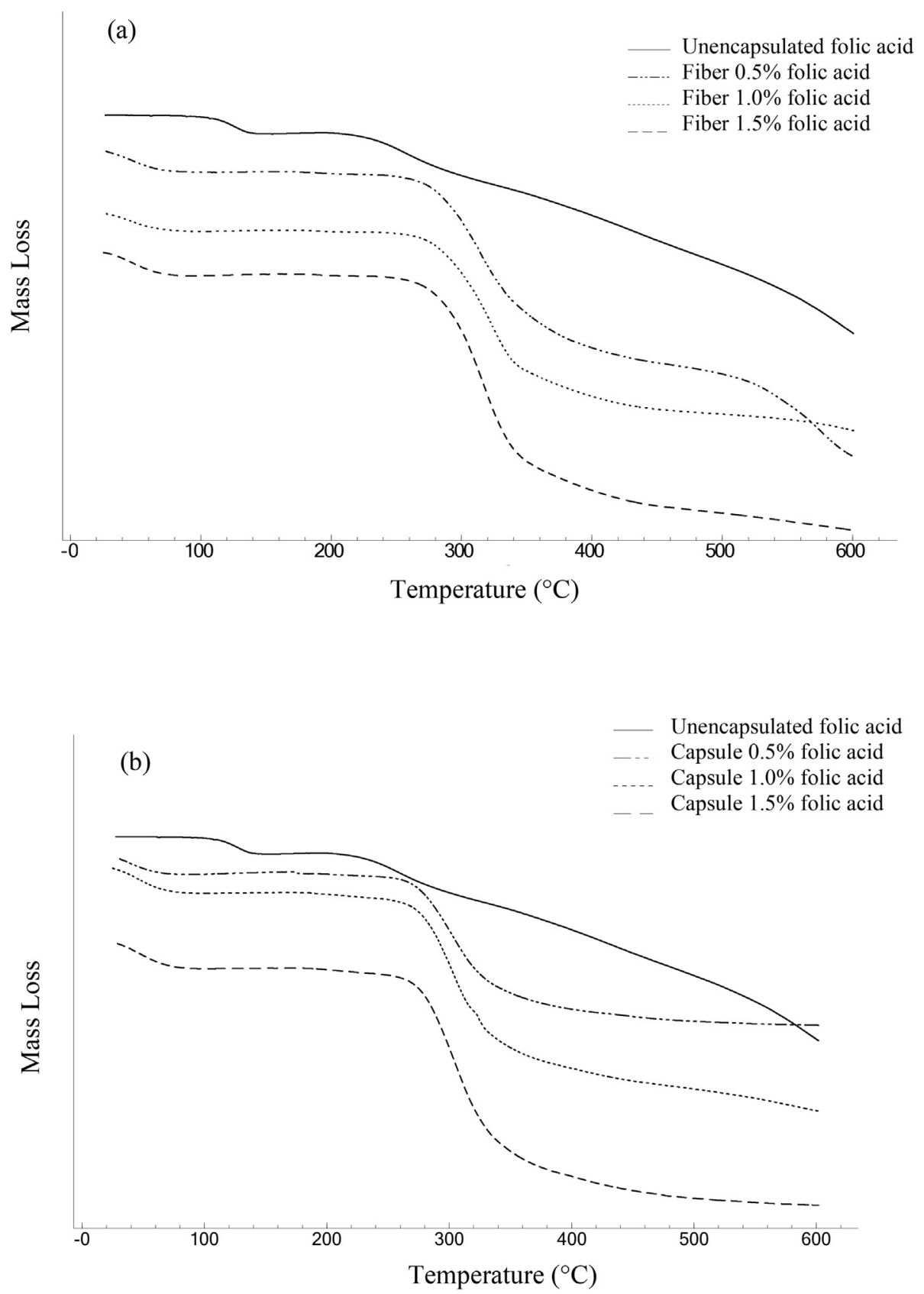

Fig. 4. TGA curves: (a) pure folic acid and zein fibers with $0.5,1.0$, and $1.5 \%$ folic acid, (b) pure folic acid and zein capsules with 0.5 , 1.0 , and $1.5 \%$ folic acid.

Table 2

Encapsulation efficiency and thermal resistance of encapsulated folic acid in the form of zein fibers or capsules.

\begin{tabular}{|c|c|c|c|c|c|c|}
\hline \multirow[t]{3}{*}{ Form of encapsulated } & \multirow[t]{3}{*}{ Folic acid (\%) } & \multirow{3}{*}{$\begin{array}{l}\text { Encapsulation efficiency } \\
(\%)^{*}\end{array}$} & \multirow[t]{2}{*}{ No exposure } & \multicolumn{3}{|c|}{ Thermal treatment $\left({ }^{\circ} \mathrm{C}\right)$} \\
\hline & & & & 100 & 140 & 180 \\
\hline & & & Folic acid $(\mu \mathrm{g} / \mathrm{n}$ & & & \\
\hline \multirow[t]{2}{*}{ Unencapsulated folic acid } & & - & $17.17 \pm 1.35^{\mathrm{a}}$ & $17.62 \pm 1.98^{\mathrm{ab}}$ & $15.60 \pm 0.14^{\mathrm{b}}$ & $5.44 \pm 0.08^{c}$ \\
\hline & 0.5 & $92.9 \pm 0.1^{\mathrm{a}}$ & $2.91 \pm 0.15^{\mathrm{a}}$ & $2.71 \pm 0.25^{\mathrm{a}}$ & $2.85 \pm 0.03^{\mathrm{a}}$ & $2.67 \pm 0.16^{\mathrm{a}}$ \\
\hline \multirow[t]{3}{*}{ Fibers } & 1.0 & $91.7 \pm 0.1^{\mathrm{a}}$ & $6.38 \pm 0.13^{\mathrm{a}}$ & $6.53 \pm 0.44^{\mathrm{a}}$ & $6.28 \pm 0.36^{\mathrm{a}}$ & $6.00 \pm 0.12^{\mathrm{a}}$ \\
\hline & 1.5 & $82.1 \pm 0.1^{\mathrm{b}}$ & $9.73 \pm 1.20^{\mathrm{a}}$ & $9.10 \pm 0.94^{\mathrm{ab}}$ & $7.95 \pm 0.37^{\mathrm{b}}$ & $8.88 \pm 0.07^{\mathrm{ab}}$ \\
\hline & 0.5 & $98.6 \pm 2.3^{\mathrm{a}}$ & $2.74 \pm 0.15^{\mathrm{a}}$ & $2.84 \pm 0.22^{\mathrm{a}}$ & $2.83 \pm 0.08^{\mathrm{a}}$ & $2.84 \pm 0.05^{\mathrm{a}}$ \\
\hline \multirow[t]{2}{*}{ Capsules } & 1.0 & $92.9 \pm 0.3^{\mathrm{a}}$ & $6.22 \pm 0.03^{\mathrm{a}}$ & $5.63 \pm 0.24^{b}$ & $5.63 \pm 0.21^{b}$ & $5.60 \pm 0.01^{b}$ \\
\hline & 1.5 & $73.7 \pm 1.7^{\mathrm{b}}$ & $8.84 \pm 0.55^{\mathrm{a}}$ & $7.26 \pm 0.19^{b}$ & $7.49 \pm 0.06^{\mathrm{b}}$ & $7.69 \pm 0.27^{b}$ \\
\hline
\end{tabular}

* Encapsulation efficiency: Values with different letters in the same column for fibers or capsules are significantly different by Tukey's test (p $<.05$ ).

${ }^{* *}$ Folic acid content: Values with different letters in the same row are significantly different by Tukey's test $(p<.05)$. 
Table 3

Encapsulation efficiency and UVA irradiation resistance of encapsulated folic acid in the form of zein fibers or capsules.

\begin{tabular}{|c|c|c|c|c|c|c|}
\hline \multirow[t]{3}{*}{ Form of encapsulation } & \multirow[t]{3}{*}{ Folic acid (\%) } & \multirow{3}{*}{$\begin{array}{l}\text { Encapsulation efficiency } \\
(\%)^{*}\end{array}$} & \multirow[t]{2}{*}{ No exposure } & \multicolumn{3}{|c|}{ UVA irradiation time $(\mathrm{h})$} \\
\hline & & & & 1 & 12 & 24 \\
\hline & & & Folic acid $(\mu \mathrm{g} / \mathrm{r}$ & & & \\
\hline \multirow[t]{2}{*}{ Unencapsulated folic acid } & & - & $17.17 \pm 1.35^{\mathrm{a}}$ & $12.58 \pm 0.62^{\mathrm{b}}$ & $12.05 \pm 1.44^{\mathrm{b}}$ & $14.07 \pm 0.44^{\mathrm{b}}$ \\
\hline & 0.5 & $92.9 \pm 0.1^{\mathrm{a}}$ & $2.91 \pm 0.15^{\mathrm{a}}$ & $2.59 \pm 0.33^{\mathrm{a}}$ & $2.93 \pm 0.29^{\mathrm{ab}}$ & $2.27 \pm 0.13^{\mathrm{b}}$ \\
\hline \multirow[t]{3}{*}{ Fibers } & 1.0 & $91.7 \pm 0.1^{\mathrm{a}}$ & $6.38 \pm 0.13^{\mathrm{a}}$ & $5.05 \pm 0.32^{\mathrm{ab}}$ & $5.05 \pm 0.88^{\mathrm{b}}$ & $4.85 \pm 0.58^{\mathrm{b}}$ \\
\hline & 1.5 & $82.1 \pm 0.1^{\mathrm{b}}$ & $9.73 \pm 1.20^{\mathrm{a}}$ & $8.02 \pm 1.00^{\mathrm{ab}}$ & $7.92 \pm 0.48^{b}$ & $8.88 \pm 0.05^{\mathrm{ab}}$ \\
\hline & 0.5 & $98.6 \pm 2.3^{\mathrm{a}}$ & $2.74 \pm 0.15^{\mathrm{a}}$ & $2.50 \pm 0.16^{\mathrm{a}}$ & $2.68 \pm 0.13^{\mathrm{a}}$ & $2.50 \pm 0.30^{\mathrm{a}}$ \\
\hline \multirow[t]{2}{*}{ Capsules } & 1.0 & $92.9 \pm 0.3^{\mathrm{a}}$ & $6.22 \pm 0.03^{\mathrm{a}}$ & $5.04 \pm 0.53^{\mathrm{ab}}$ & $4.67 \pm 0.30^{\mathrm{b}}$ & $5.56 \pm 1.1^{\mathrm{ab}}$ \\
\hline & 1.5 & $73.7 \pm 1.7^{\mathrm{b}}$ & $8.84 \pm 0.55^{\mathrm{a}}$ & $7.75 \pm 0.51^{\mathrm{a}}$ & $7.93 \pm 1.30^{\mathrm{a}}$ & $7.88 \pm 1.60^{\mathrm{a}}$ \\
\hline
\end{tabular}

* Encapsulation efficiency: Values with different letters in the same column for fibers or capsules are significantly different by Tukey's test (p < .05).

** Folic acid content: Values with different letters in the same row are significantly different by Tukey's test (p < .05).

Folic acid was identified by the presence of the $[\mathrm{M}+\mathrm{H}]^{+} m / z$ 442.1469. The content of the folic acid submitted to the heat treatment was lower when compared to the folic acid control (without thermal treatment). In addition, the degradation products including 6-carboxypterin (PCA), p-aminobenzoyl-L-glutamic acid (pABGA), p-aminobenzoic acid (PABA), and pteroic acid (PA) were identified by the presence of the $[\mathrm{M}+\mathrm{H}]^{+} \mathrm{m} / z$ 208.0465, 267.0975, 138.0549, and 313.1043 , respectively. Vora et al. (2002) studied the thermostability of folic acid and suggested that initially the glutamate fraction of folic acid breaks, leaving the amide as the major component. Then the pterin and PABA decompose in an overlapping mechanism. These authors also reported that at $195^{\circ} \mathrm{C}$ it is not possible to discern the groups present, indicating a complete decomposition of the vitamin at this temperature. According to Ball (2006), folic acid has no defined melting point, but at $250{ }^{\circ} \mathrm{C}$ an important degree of carbonization is already observed.

The degradation compounds pABGA $\left([\mathrm{M}+\mathrm{H}]^{+} m / z 267.0975\right)$ and PA $\left([\mathrm{M}+\mathrm{H}]^{+} m / z\right.$ 313.1043) were identified after exposition of folic acid to UVA irradiation for $24 \mathrm{~h}$. The pABGA is formed by the photochemical cleavage of the $\mathrm{C} 9 \mathrm{-N} 10$ bond, while the PA is the product of amide linkage of folic acid between the glutamate and PABA. Akhtar, Khan, and Ahmad $(1999,2003)$ studied the effects of different pH on photodegradation of folic acid by UV and found PABA, PCA, pABGA, and PA as its major degradation products.

\section{Conclusion}

Polymer solutions of zein containing encapsulated folic acid were able to form continuous and uniform ultrafine fibers and nanocapsules by electrospinning and electrospraying processes. Through thermogravimetric analysis, it was possible to observe an increase in the thermal resistance of folic acid when it was incorporated in the fibers or capsules. Zein and fiber capsules showed high encapsulation efficiency for folic acid (> 80\%). Unencapsulated folic acid showed intense degradation when exposed to $180{ }^{\circ} \mathrm{C}(70 \%$ loss); however, while encapsulated in fiber or capsules the vitamin was stable. The photodegradation of unencapsulated folic acid was approximately $26 \%$ after $1 \mathrm{~h}$ of UVA irradiation; however, when folic acid was incorporated into zein fibers, radiation resistance was generally observed. Zein fibers and capsules with folic acid present promising characteristics for application in foods that require thermal processing and exposure to irradiation.

\section{Acknowledgments}

We would like to thank CAPES (88882.156946/2014-01), Embrapa, CNPq, FAPERGS (17/2551-0000912-6), SDECT-RS, CEME-SUL, and Pólo de Inovação Tecnológica em Alimentos da Região Sul.

\section{Conflict of interest}

The authors declare that there is no conflict of interest.

\section{References}

Aceituno-Medina, M., Mendoza, S., Lagaron, J. M., \& Lopez-Rubio (2015). A photoprotection of folic acid upon encapsulation in food-grade amaranth (Amaranthus hypochondriacus L.) protein isolate - pullulan electrospun fibers. LWT - Food Science and Technology, 62, 970-975.

Acevedo-Fani, A., Soliva-Fortuny, R., \& Martín-Belloso, O. (2018). Photo-protection and controlled release of folic acid using edible alginate/chitosan nanolaminates. Journal of Food Engineering, 229, 72-82.

Agrawal, A., Murphy, R. F., \& Agrawal, D. K. (2007). DNA methylation in breast and colorectal cancers. Modern Pathology, 20, 711-721.

Akhtar, M. J., Khan, M. A., \& Ahmad, I. (1999). Photodegradation of folic acid in aqueous solution. Journal of Pharmaceutical and Biomedical Analysis, 19, 269-275.

Akhtar, M. J., Khan, M. A., \& Ahmad, I. (2003). Identification of photoproducts of folic acid and its degradation pathways in aqueous solution. Journal of Pharmaceutical and Biomedical Analysis, 31, 579-588.

Altan, A., Aytac, Z., \& Uyar, T. (2018). Carvacrol loaded electrospun fibrous films from zein and poly(lactic acid) for active food packaging. Food Hydrocolloids, 81, 48-59.

Ariyarathna, I. R., \& Karunaratne, D. N. (2015). Use of chickpea protein for encapsulation of folateto enhance nutritional potency and stability. Food and Bioproducts Processing Food and Bioproducts Processing, 95, 76-82.

Assadpour, E., Jafari, S.-M., \& Maghsoudlou.Y. (2017). Evaluation of folic acid release from spray dried powder particles of pectin-whey protein nano-capsules. International Journal of Biological Macromolecules, 95, 238-244.

Aytac, Z., Kusku, S. I., Durgun, E., \& Uya, T. (2016). Encapsulation of gallic acid/cyclodextrin inclusion complex in electrospun polylactic acid nanofibers: Release behavior and antioxidant activity of gallic acid. Materials Science and Engineering, 63, 231-239.

Ball, F. M. G. (2006). Vitamins in foods: analysis, bioavailability, and stability. New York: Taylor \& Francis Group.

Baspinar, Y., Ustundas, M., Bayraktar, O., \& Sezgin, C. (2018). Curcumin and piperine loaded zein-chitosan nanoparticles: Development and in-vitro characterisation. Saudi Pharmaceutical Journal, 26, 323-334.

Bhardwaj, N., \& Kundu, S. C. (2010). Electrospinning: A fascinating fiber fabrication technique. Biotechnology Advances, 28, 325-347.

Bhushani, J. A., \& Anandharamakrishnan, C. (2014). Electrospinning and electrospraying techniques: Potential food based applications. Food Science \& Technology, 38, 21-33.

Brahatheeswaran, D., Mathew, A., Aswathy, R. G., Nagaoka, Y., Venugopal, K., Yoshida, Y., ... Sakthikumar, D. (2012). Hybrid fluorescent curcumin loaded zein electrospun nanofibrous scaffold for biomedical applications. Biomedical Materials, 7, 45-50.

Chen, Z., Xiumei, M., \& Fengling, Q. (2007). Electrospinning of collagen-chitosan complex. Materials Letters, 61, 3490-3494.

Dashdorj, U., Reyes, M. K., Unnithan, A. R., Tiwari, A. P., Tumurbaatar, B., Park, C. H., \& Kim, C. S. (2015). Fabrication and characterization of electrospun zein/ag nanocomposite mats for wound dressing applications. International Journal of Biological Macromolecules, 80, 1-7.

Delchier, N., Herbig, A.-L., Rychlik, M., \& Renard, C. M. (2016). Folates in fruits and vegetables: Contents, processing, and stability. Comprehensive Reviews in Food Science and Food Safety, 15, 506-528.

Fernandez, A., Torres-Giner, S., \& Lagaron, J. M. (2009). Novel route to stabilization of bioactive antioxidants by encapsulation in electrospun fibers of zein prolamine. Food Hydrocolloids, 23, 1427-1432.

Fukuwatari, T., Fujita, M., \& Shibata, K. (2009). Effects of UVA irradiation on the concentration of folate in human blood. Bioscience, Biotechnology, and Biochemistry, 73, 322-327.

Gazzali, A. M., Lobry, M., Colombeau, L., Acherar, S., Azaïs, H., Mordon, S., ... Frochot, C. (2016). Stability of folic acid under several parameters. European Journal of Pharmaceutical Sciences, 93, 419-430.

Guo, H. X., Heinamaki, J., \& Yliruusi, J. (2008). Stable aqueous film coating dispersion of 
zein. Journal of Colloid and Interface Science, 32, 478-484.

Jastrebova, J., Axelsson, M., Strandler, H. S., \& Jägerstad, M. (2013). Stability of dietary 5-formyl-tetrahydrofolate and its determination by HPLC: A pilot study on impact of $\mathrm{pH}$, temperature and antioxidants on analytical results. European Food Research and Technology, 237, 747-754.

Jaworek, A., \& Sobczyk, A. T. (2008). Electrospraying route to nanotechnology: Na overview. Journal of Electrostatics, 66, 197-219.

Juzeniene, A., Tam, T. T. T., Iani, V., \& Moa, J. (2013). The action spectrum for folic acid photodegradation in aqueous solutions. Journal of Photochemistry and Photobiology B: Biology, 1, 11-16.

Mori, C. L. S. O., Passos, N. A., Oliveira, J. E., Mattoso, L. H. C., Mori, F. A., Carvalho, A. G., ... Tonoli, G. H. D. (2014). Electrospinning of zein/tannin bio-nanofibers. Industrial Crops and Products, 52, 298-304.

Neo, Y. P., Ray, S., Jin, J., Gizdavic-Nikolaidis, M., Nieuwoudt, M. K., \& Liu, D. (2013). Encapsulation of food grade antioxidant in natural biopolymer by electrospinning technique: A physicochemical study based on zein-gallic acid system. Food Chemistry, 136, 1013-1021.

Nguyen, M. T., Oey, I., Verlinde, P., Van Loey, A., \& Hendrickx, M. (2003). Model studies on the stability of folic acid and 5-methyltetrahydrofolic acid degradation during thermal treatment in combination with high hydrostatic pressure. Journal of Agricultural and Food Chemistry, 51, 3352-3357.

Nukolova, N. V., Oberoi, H. S., Cohen, S. M., Kabanov, A. V., \& Bronich, T. K. (2011). Folate-decorated nanogels for targeted therapy of ovarian cancer. Biomaterials, 32, 5417-5426.

Padgett, T., Han, I., \& Dawson, P. (1998). Incorporation of food-grade antimicrobial compounds into biodegradable packaging films. Journal of Food Protection, 61, 1330-1335.

Peñalva, R., Esparza, I., Gonzalez-Navarro, C. J., Quincoces, G., Peñuelas, I., \& Irache, J. M. (2015). Zein nanoparticles for oral folic acid delivery. Journal of Drug Delivery Science and Technology, 30, 450-457.

Pérez-Masiá, R., López-Nicolás, R., Periago, M. J., Ros, G., Lagaron, J. M., \& López-Rubio, A. (2015). Encapsulation of folic acid in food hydrocolloids through nanospray drying and electrospraying for nutraceutical applications. Food Chemistry, 168, 124-133.
Prasanna, B. M., Vasal, S. K., Kassahun, B., \& Singh, N. N. (2001). Quality protein maize. Current Science, 81, 1308-1319.

Saowakon, W., \& Suanantha, P. (2014). Effect of entrapped $\alpha$-tocopherol on mucoadhesivity and evaluation of the release, degradation, and swelling characteristics of zein-chitosan composite electrospun fibers. Journal of Food Engineering, 120, 110-117.

Scott, J., Rebeill, F., \& Fletcher, J. (2000). Review: Folic acid and folates: The feasibility for nutritional enhancement in plant foods. Journal of the Science of Food and Agriculture, 80(795-824), 2000.

Selling, G. W., Biswas, A., Patel, A., Walls, D. J., Dunlap, C., \& Wei, Y. (2007). Impact of solvent on electrospinning of zein and analysis of resulting fibers. Macromolecular Chemistry and Physics, 208, 1002-1010.

Silva, C., Keating, E., \& Pinto, E. (2017). The impact of folic acid supplementation on gestational and long term health: Critical temporal windows, benefits and risks. Porto Biomedical Journal, 2, 315-332.

Sudimack, J., \& Lee, R. J. (2000). Targeted drug delivery via the folate receptor. Advanced Drug Delivery Reviews, 41, 147-162.

Teng, X., Ren, J., \& Gu, S. (2007). Preparation and characterization of porous PDLLA/HA composite foams by supercritical carbon dioxide technology. Journal of Biomedical Materials Research Part B: Applied Biomaterials. 81, 185-193.

Torres-Giner, S., Martinez-Abad, A., Ocio, M. J., \& Lagaron, J. M. (2010). Stabilization of a nutraceutical Omega-3 fatty acid by encapsulation in ultrathin electrosprayed zein prolamine. Journal of Food Science, 75, 69-79.

Vora, A., Riga, A., Dollimore, D., \& Alexander, K. S. (2002). Thermal stability of folic acid. Thermochim Acta, 392-393, 209-220.

Wen, H. F., Yang, C., Yu, D. G., Li, X. Y., \& Zhang, D. F. (2016). Electrospun zein nanoribbons for treatment of lead-contained wastewater. Chemical Engineering Journal, $290,263-272$

Yang, J.-M., Zha, L.-S., Yu, D.-G., \& Liu, J. (2013). Coaxial electrospinning with acetic acid for preparing ferulic acid/zein composite fibers with improved drug release profiles. Colloids and Surfaces B: Biointerfaces, 102, 737-743.

Zussman, E. (2011). Encapsulation of cells within electrospun fibers. Polymers for Advanced Technologies, 22, 366-371. 